\title{
Determinants of species richness patterns in the Netherlands across multiple taxonomic groups
}

\author{
M. A. Schouten · P. A. Verweij · A. Barendregt · R. M. J. C. Kleukers • \\ V. J. Kalkman · P. C. de Ruiter
}

Received: 24 October 2007 / Accepted: 28 August 2008/Published online: 24 September 2008

(C) Springer Science+Business Media B.V. 2008

\begin{abstract}
We examined the species richness patterns of five different species groups (mosses, reptiles and amphibians, grasshoppers and crickets, dragonflies, and hoverflies) in the Netherlands $\left(41,500 \mathrm{~km}^{2}\right)$ using sampling units of $5 \times 5 \mathrm{~km}$. We compared the spatial patterns of species richness of the five groups using Spearman's rank correlation and used a stepwise multiple regression generalized linear modelling (GLM) approach to assess their relation with a set of 36 environmental variables, selected because they can be related to the several hypotheses on biodiversity patterns. Species richness patterns of the five groups were to a certain extent congruent. Our data suggest that environmental heterogeneity (in particular habitat heterogeneity) is one of the major determinants of variation in species richness within these five groups. We found that for taxonomic groups comprising a low number of species, our regression model explained more of the variability in species richness than for taxonomic groups with a large number of species.
\end{abstract}

Keywords Conservation · Crickets · Dragonflies · Generalized linear modelling · Grasshoppers · Hoverflies · Herpetofauna $\cdot$ Mosses $\cdot$ Species richness · The Netherlands

M. A. Schouten $(\bowtie) \cdot$ A. Barendregt · P. C. de Ruiter Department of Environmental Sciences, Copernicus Institute for Sustainable Development and Innovation, Utrecht University, P.O. Box 80115, 3508 TC Utrecht, The Netherlands e-mail: m.a.schouten@uu.nl

P. A. Verweij

Department of Science, Technology and Society, Copernicus Institute for Sustainable Development and Innovation, Utrecht University, P.O. Box 80115, 3508 TC Utrecht, The Netherlands

R. M. J. C. Kleukers · V. J. Kalkman

European Invertebrate Survey - The Netherlands, P.O. Box 9517, 2300 RA Leiden, The Netherlands

P. C. de Ruiter

Soil Science Research Centre, Wageningen University, P.O. Box 47, 6700 AA Wageningen, The Netherlands 


\section{Introduction}

Species richness is not equally distributed across the earth's surface. Why some areas comprise more species than others has been subject of research since the beginning of the nineteenth century. The serious decline in species richness that has occurred over the past century (e.g. Chapin et al. 2000; Millennium Ecosystem Assessment 2005) only increased the urgency to acquire an understanding of species richness distribution. Knowledge of the spatial distribution of species richness are needed to develop effective conservation strategies. The identification of biodiversity hotspots, areas that are highly diverse in terms of species richness, rarity and/or endemism (e.g. Margules et al. 2002), is frequently done in support of conservation strategies as this can help to optimize conservation efforts in response to space, time, money, and knowledge constraints (Myers et al. 2000). However, a general understanding of the relationship between species richness and the environment is also of great importance (Prendergast et al. 1993; Williams et al. 2002). Hence, if we are able to identify patterns in species richness and if we are also able to identify the crucial environmental factors underlying these patterns, we then are able to derive the requirements to protect biodiversity effectively and efficiently.

Species richness patterns are scale-dependent (Levin 1992, 2000). The scale of the investigation determines the patterns and processes that will be detected (Godfray and Lawton 2001). Latitudinal gradients in species richness (with the tropics being more species rich than the northern and southern hemisphere) are observed for a wide range of taxonomic groups (Gaston 2000). Numerous mechanisms that may underlie these latitudinal gradients in species richness have been proposed so far. Among them are null [e.g. the mid-domain effect (Colwell and Lees 2000)] and neutral models (Hubbell 2001), but also explanations based on productivity (energy availability, climate), evolutionary time, environmental stability and heterogeneity and species interactions. Even for this wellestablished pattern, no consensus on the underlying mechanism has yet been reached. No single mechanism can adequately explain all variation; it is most likely that spatial patterns in species richness are the result of a combination of several mechanisms (Gaston and Blackburn 1990). At a finer spatial scale species richness may vary along several environmental gradients: altitude (e.g. Rahbek 1995); energy availability (e.g. Currie 1991; Gaston 2000), climate (e.g. Currie 1991; Rohde 1992), habitat heterogeneity (e.g. Rahbek and Graves 2000; Kerr 2001), and disturbance (Huston 1994) are frequently considered as important determinants of regional patterns in species richness.

The widely reported decline of biodiversity (e.g. Millennium Ecosystem Assessment 2005) is also felt in the Netherlands, a highly industrialized and densely populated country. The Netherlands obliged itself to preserve representative sets of biodiversity by signing the Convention on Biological Diversity (UNCED) and nature conservation policy to implement this goal has been developed accordingly. Like in many other countries, vascular plant species and breeding birds fulfil a key function in the conservation of biodiversity in the Netherlands. Together, these groups comprise the majority of the target species for nature conservation (Bal et al. 2001). However, they only represent a small part of the 42,000 species estimated to occur in the Netherlands (van Nieukerken and van Loon 1995). Patterns of species richness do not necessarily coincide for different taxonomic groups (e.g. Prendergast et al. 1993; Myers et al. 2000; Tardif and DesGranges 1998; Harcourt 2000) and, therefore, it is unlikely that they represent the broad spectrum of biodiversity. Moreover, there is no reason to assume that cryptobiota or lower taxa of plants are less at risk or of less importance then the well-studied vascular plant, bird and vertebrate species. It is only recently, that Red Lists are also being constructed for less conspicuous species 
groups such as molluscs and various insect taxa. However, a general understanding of the diversity patterns of such groups is still lacking.

In order to see if the focus of nature conservation on vascular plants and breeding birds is legitimate we aim at obtaining a broader view on biodiversity in this study. Therefore, we focus on species richness patterns of a broad array of taxonomic groups: mosses (Bryophyta), grasshoppers and crickets (Orthoptera), hoverflies (Syrphidae), dragonflies (Odonata), and herpetofauna (Reptilia and Amphibia). We first compare the spatial patterns in species richness among these five taxonomic groups in the Netherlands. Secondly, we present the results of a multiple regression approach to assess how a set of 36 environmental variables, linked to the hypotheses on biodiversity discussed above can be related to the observed patterns in species richness. We compare the biodiversity patterns of the five studied groups with those of plants and birds and results are discussed in the light of nature conservation policy.

\section{Material and methods}

\section{Research area}

The Netherlands is a relatively small country $\left(41,500 \mathrm{~km}^{2}\right)$ located in northwestern Europe, with a diverse assemblage of habitats ranging from agricultural landscapes and wetlands below sea level to loess hills and extensive forested areas. High population density, industrialisation, and contemporary land-use practices have radically altered the natural landscape. Series of major land use changes, having their peak in the 1960s, have had a severe impact on the landscape as they have led not only to the intensification of land use, but also to the abandonment of lands, and afforestation.

\section{Species occurrence data}

A $5 \times 5 \mathrm{~km}$ UTM grid of the Netherlands was constructed using ArcView GIS 3.3 (ESRI, USA). Only those grid squares consisting for more than $50 \%$ of terrestrial area (located within the Netherlands) were taken into account $(N=1393)$. Species lists for all grid squares were derived from several nationwide databases on species occurrences in the Netherlands. Data on the distribution of dragonflies, grasshoppers and crickets, and hoverflies were derived from the database of the European Invertebrate Survey (EISNederland), data on the distribution of moss species came from the Bryological and Lichenological Working Group (BLWG) and data on the occurrence of the herpetofauna were obtained from the Reptile, Amphibian and Fish Research of the Netherlands (RAVON). These databases comprise a diverse assortment of museum records, data from monitoring schemes, species lists of inventory trips, and independent records collected over a large period of time by many volunteers (see Table 1). Data are generally collected in a rather ad hoc fashion, which may result in taxonomically, geographically and temporally biased records (e.g. Rich 1998; Dennis et al. 1999; Williams et al. 2002). Data are not freely available, for enquiries please contact VOFF (http://www.voff.nl) or the individual organisations directly.

For all grid squares the number of species per taxonomic group was counted, discarding records that were collected prior to 1965 . Older data probably are not representative anymore because of major land use changes that took place in the 1960s. Of course, environmental conditions in the Netherlands have gradually changed since then, but there 
Table 1 Number of species, number of records, approximate number of collectors, time span over which data are collected, and origin of data ( $C=$ museum collections, $F=$ observations in the field, $L=$ literature, $M=$ monitoring schemes) for the five taxonomic groups

\begin{tabular}{|c|c|c|c|c|c|}
\hline & Hoverflies & Herpetofauna & $\begin{array}{l}\text { Grasshoppers } \\
\text { and crickets }\end{array}$ & Dragonflies & Mosses \\
\hline No. of species & 327 & 24 & 45 & 71 & 507 \\
\hline No. of records & 372,118 & 233,206 & 70,000 & 220,000 & 875,000 \\
\hline $\begin{array}{l}\text { No. of } \\
\text { collectors }\end{array}$ & 450 & 1000 & NA & 200 & 300 \\
\hline Origin & $\mathrm{C}, \mathrm{F}, \mathrm{L}$ & $\mathrm{F}, \mathrm{M}$ & $\mathrm{C}, \mathrm{F}, \mathrm{L}$ & $\mathrm{C}, \mathrm{F}, \mathrm{L}, \mathrm{M}$ & $\mathrm{C}, \mathrm{F}, \mathrm{L}, \mathrm{M}$ \\
\hline
\end{tabular}

NA no data available

is always a trade-off between data quantity and accuracy when using this kind of species occurrence data. By adopting 1965 as a boundary we ensure enough data and ruling out several important environmental changes.

Environmental data

Data on land cover types were derived from the LGN4 land cover map (Alterra 2001). We calculated habitat heterogeneity of each grid square using Shannon's diversity index:

$$
H^{\prime}=-\Sigma p_{i} \ln p_{i}
$$

where $p_{i}$ is the proportion of the $i$ th land cover type. For this calculation the 39 land cover categories of the LGN4 land cover map were lumped into 15 habitat types (agricultural land, bare soil, coniferous forest, deciduous forest, drift sand, dune vegetation, fen areas, freshwater, heath, marsh, natural grassland, peat bog, salt marshes, scrubland and urbanized area). Mean elevation and elevation range were derived from the Dutch national digital elevation model (Rijkswaterstaat 2002). Soil types were abstracted from the Dutch soil type map (Steur and Heijink 1992). Heterogeneity of soil types was calculated following the same procedure as for habitat heterogeneity. Nitrogen deposition (1995-1997 means) data were derived from the STONE model (Overbeek et al. 2002), while available nitrogen (1991-1997 means) was obtained from Bio et al. (1999). A map of the age of the Dutch landscape was constructed using literature and topographical maps from ca. 1850 to 2002 (Cormont et al. 2004). Data on five climatic variables were obtained from the Royal Netherlands Meteorological Institute (KNMI 2002). Relative humidity in spring (\%), duration of sunshine $(\mathrm{h})$, amount of radiation (joule $\left./ \mathrm{m}^{2}\right)$, temperature $\left({ }^{\circ} \mathrm{C}\right)$ and precipitation surplus (mm) are given as the long-term annual means over the period from 1971 to 2000 based on the monthly values of 283 meteorological stations.

Statistical analyses

\section{Comparing species richness patterns between taxonomic groups}

Spearman's rank correlation was used to determine the congruence of species richness patterns among the five taxonomic groups. A combined index of species richness for all taxonomic groups was constructed scaling maximum species richness for each group to 100 and summing the percentages of maximum species richness of all groups except the taxonomic group for which the comparison was made for each grid square. For this 
analysis we only used those grid squares $(N=528)$ that were sufficiently surveyed (see modelling species diversity) for all five taxonomic groups.

\section{Modelling species richness}

We used a stepwise multiple regression approach to test the relationship between the set of environmental variables (see Table 2) and the observed species richness of five taxonomic groups. As species counts are discrete values we applied generalized linear modelling (GLM; McCullagh and Nelder 1989) and selected a Poisson error distribution. The response variable was linked to the set of predictor variables using a logarithmic link function (Crawley 1993).

Collinearity among the predictor variables was assessed by evaluation of Pearson correlations, using data for all grid squares $(N=1393)$. Spatial autocorrelation in the dataset could cause non-significant correlations to appear as significant ones as the confidence interval around a Pearson correlation coefficient estimated by the classical procedure is narrower than when it is calculated correctly (Legendre 1993). Therefore, we used a modified $t$ test (Dutilleul 1993) to produce unbiased estimates of the significance of the correlations. In order to account for the collinearity of the predictor variables we also tested the performance of principal component analysis (PCA). The usage of PCA axes, however, did not produce better results than the individual variables. For interpretational reason we therefore opted for the usage of individual variables rather than PCA axes.

In order to account for sampling bias in the species occurrence datasets, we only used the $75 \%$ most frequently surveyed grid squares from each physical geographical region in the Netherlands (Fig. 1). In this way, grid squares that are incompletely surveyed $(N=348)$ were excluded from the analysis. This subset of grid squares was then randomly divided into an explanatory set (two-thirds of the grid squares) used for model building and an evaluation set (one-third of the grid squares) that was used for model evaluation.

For each species group we constructed a stepwise multiple regression model based on the forward selection of the explanatory variables (see Nicholls 1989; Austin 1980) using S-PLUS 6.0 (Insightful Corp.). To account for possible curvilinear relationships, explanatory variables were included as quadratic functions. First, the variable that accounted for the most important change in deviance was included in the model. Change in explained variation was tested using an $F$ ratio test with a 5\% significance level. Then, a forward stepwise procedure was used to enter the variables into the model. This means that all remaining variables were tested for their significance, adding the variable that explained the largest part of remaining variation. After each inclusion, we used successive exclusion of redundant terms via stepwise backward deletion, removing terms that had become nonsignificant. This procedure was repeated until no more variables remained that accounted for a statistically significant $(P<0.05)$ change in deviance.

In order to determine the accuracy of the species richness models, the percentage of explained deviance was calculated for each model (see Dobson 1999). We evaluated the models' accuracy by fitting it to the evaluation set and compared the predicted and observed species richness using Spearman's rank correlation (Heikkinen and Neuvonen 1997; Maes et al. 2005).

\section{Spatial autocorrelation and residuals}

Spatial autocorrelation is a common feature of ecological variables measured across geographic space (Legendre 1993). Spatial dependence in species richness data can occur in the 
Table 2 Possible explanatory variables as used in the stepwise multiple regression modelling

\begin{tabular}{|c|c|}
\hline Variable & Description (units) \\
\hline ALT & Mean altitude (m) \\
\hline ALTR & Altitudinal range $(\mathrm{m})$ \\
\hline MLA & Maximum landscape age (years) \\
\hline DLA & Dominant landscape age (years) \\
\hline HUM & Relative humidity in spring (\%) \\
\hline SUN & Duration of sunshine $(\mathrm{h})$ \\
\hline RAD & Amount of radiation (joule $/ \mathrm{m}^{2}$ ) \\
\hline TEMP & Temperature $\left({ }^{\circ} \mathrm{C}\right)$ \\
\hline PREC & Precipitation surplus (mm) \\
\hline HST & Heterogeneity of soil types $\left(\mathrm{H}^{\prime}\right)$ \\
\hline PSS & Poor sandy soils $\left(\mathrm{km}^{2}\right)$ \\
\hline RSS & Rich sandy soils $\left(\mathrm{km}^{2}\right)$ \\
\hline CSS & Calcareous sandy soils $\left(\mathrm{km}^{2}\right)$ \\
\hline NCC & Non-calcareous clay $\left(\mathrm{km}^{2}\right)$ \\
\hline $\mathrm{CC}$ & Calcareous clay $\left(\mathrm{km}^{2}\right)$ \\
\hline NCL & Non-calcareous loam $\left(\mathrm{km}^{2}\right)$ \\
\hline PS & Peat soils $\left(\mathrm{km}^{2}\right)$ \\
\hline NDEP & Nitrogen deposition (mol/ha/year) \\
\hline NAV & Available nitrogen $\left(\mathrm{g} / \mathrm{m}^{2}\right)$ \\
\hline HLT & Heterogeneity of habitat types $\left(\mathrm{H}^{\prime}\right)$ \\
\hline AGR & Agricultural areas $\left(\mathrm{km}^{2}\right)$ \\
\hline URB & Urbanized areas $\left(\mathrm{km}^{2}\right)$ \\
\hline $\mathrm{DF}$ & Deciduous forest $\left(\mathrm{km}^{2}\right)$ \\
\hline $\mathrm{CF}$ & Coniferous forest $\left(\mathrm{km}^{2}\right)$ \\
\hline SAM & Salt marshes $\left(\mathrm{km}^{2}\right)$ \\
\hline DV & Dune vegetation $\left(\mathrm{km}^{2}\right)$ \\
\hline OS & Open sand $\left(\mathrm{km}^{2}\right)$ \\
\hline HV & Heath vegetation $\left(\mathrm{km}^{2}\right)$ \\
\hline $\mathrm{PB}$ & Peat bogs $\left(\mathrm{km}^{2}\right)$ \\
\hline SV & Sedge vegetation $\left(\mathrm{km}^{2}\right)$ \\
\hline MA & Marshes $\left(\mathrm{km}^{2}\right)$ \\
\hline FM & Fen meadows $\left(\mathrm{km}^{2}\right)$ \\
\hline ON & Other natural areas $\left(\mathrm{km}^{2}\right)$ \\
\hline FW & Freshwater $\left(\mathrm{km}^{2}\right)$ \\
\hline SW & Saltwater $\left(\mathrm{km}^{2}\right)$ \\
\hline $\mathrm{N}$ & Nature $(\%)$ \\
\hline
\end{tabular}

situation where environmental variables that determine species richness are also spatially autocorrelated (Diniz-Filho et al. 2003). Part of the spatial dependence of species richness can then be described by the explanatory variables in the regression model; part of the spatial dependence will remain in the residuals. Positive autocorrelation in the residuals of the regression model at small distances would then suggest that certain explanatory variables are missed in the analysis (Diniz-Filho et al. 2003). In order to test whether our model residuals show spatial autocorrelation we used Moran's I values (Diniz-Filho et al. 2003; 


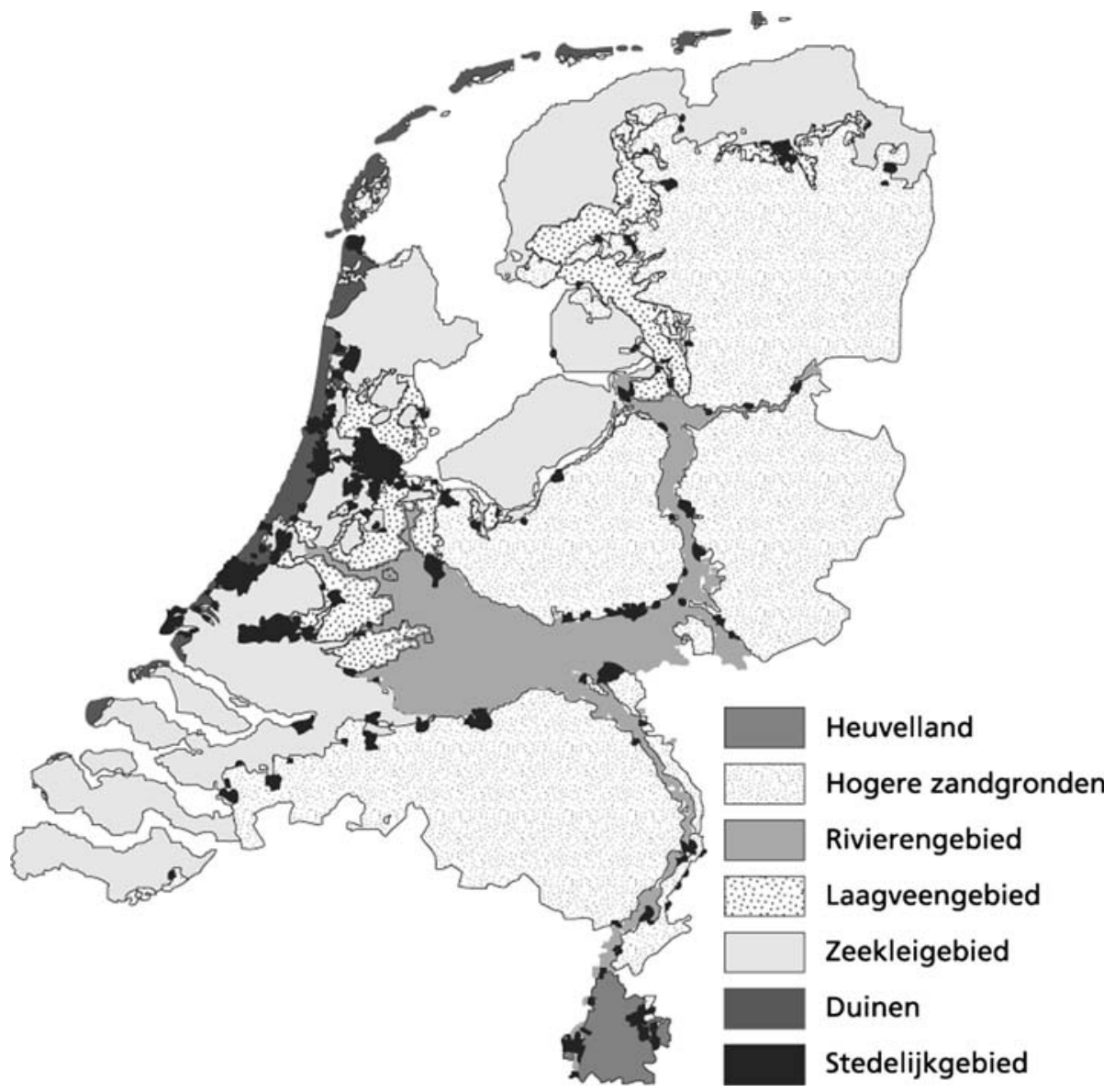

Fig. 1 Physical geographical regions of the Netherlands after Gongrijp (1989) (adapted from Bal et al. 2001)

Overmars et al. 2003). We calculated Moran's I values of the residuals of the species richness models at 7 different distance classes with a lag size of $5 \mathrm{~km}$ using sam software (Rangel et al. 2006). The statistical significance $(P<0.05)$ of the Moran's I values was assessed using randomization (Monte Carlo procedure; 200 permutations) of distances.

\section{Results}

Comparing species richness patterns among taxonomic groups

Species richness patterns of the five species groups (Fig. 2a-e) showed a clear resemblance at first sight. In the extreme southeastern part of the country a large number of species was encountered for all five taxonomic groups. The Pleistocene sand plateau in the centre and to a smaller extent also the northern part of the Netherlands is species rich for all groups except the mosses. With the exception of herpetofauna the coastal area contained large numbers of species. For the hoverflies only few areas with truly high species diversity 

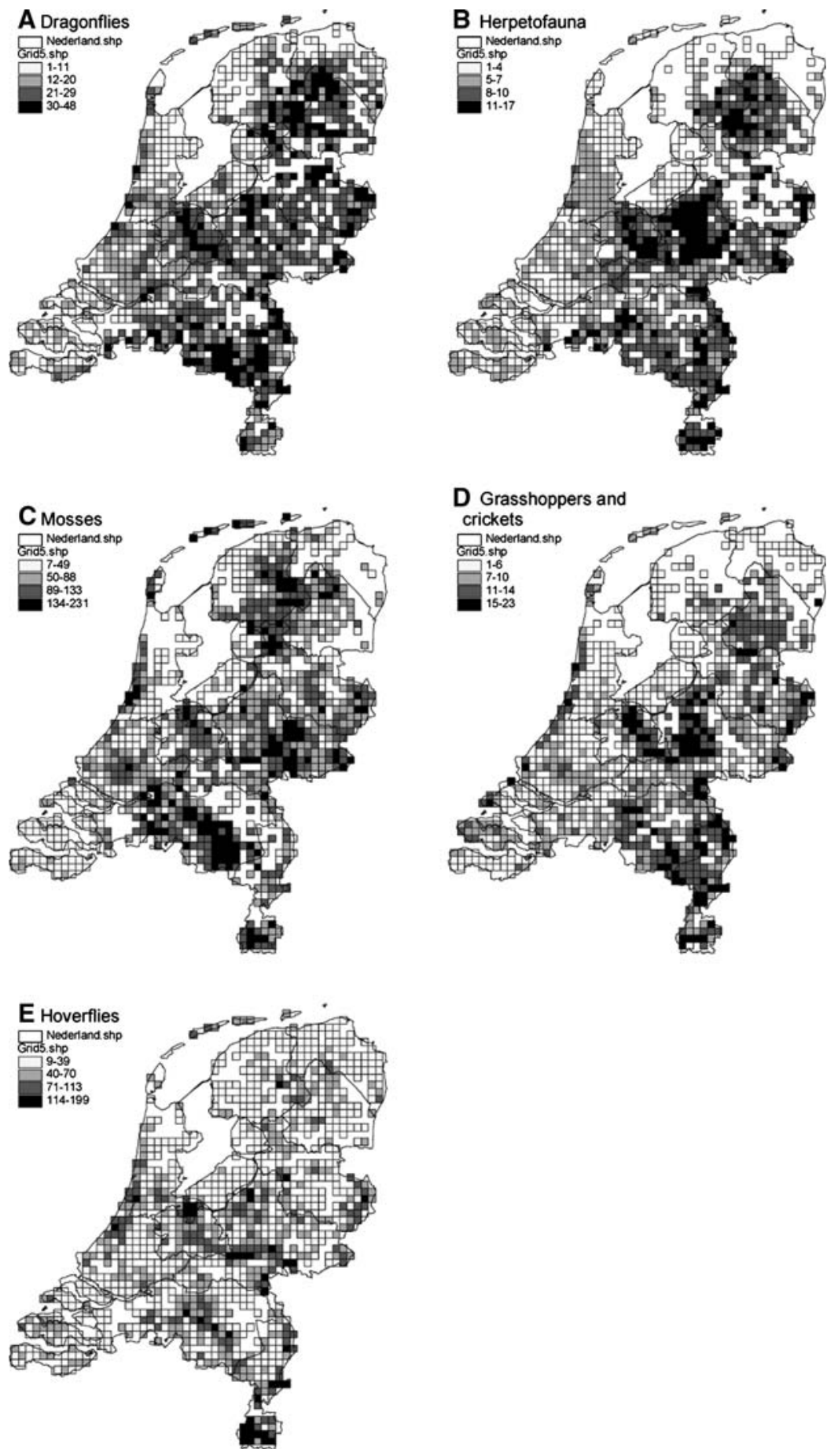

Fig. 2 Spatial patterns of species richness of (a) dragonflies, (b) herpetofauna, (c) mosses, (d) grasshoppers and crickets, and (e) hoverflies 
Table 3 Spearmans' rank correlations for the species richness of the five taxonomic groups

\begin{tabular}{llllll}
\hline & All other species & Dragonflies & Mosses & Herpetofauna & $\begin{array}{l}\text { Grasshoppers } \\
\text { and crickets }\end{array}$ \\
\hline Dragonflies & $0.804^{*}$ & - & & & \\
Mosses & $0.670^{*}$ & $0.455^{*}$ & - & & \\
$\begin{array}{l}\text { Herpetofauna } \\
\begin{array}{l}\text { Grasshoppers and } \\
\quad \text { crickets }\end{array}\end{array}$ & $0.820^{*}$ & $0.652^{*}$ & $0.390^{*}$ & - & \\
Hoverflies & $0.791^{*}$ & $0.572^{*}$ & $0.303^{*}$ & $0.643 *$ & - \\
\hline
\end{tabular}

For this correlation only the 528 grid squares that were surveyed sufficiently for all of the species groups are taken into account

* Correlation is significant at the 0.01 level

exist, the species richness is distributed more evenly across the country than for the other groups. Overall, the northern and northwestern parts of the country (agricultural areas on peat soils) were poor in species for all groups.

Taken together, only $40 \%$ of all grid squares can be marked as being sufficiently sampled for all of the five taxonomic groups. For these grid squares, correlations among species richness of the five groups tended to be high (Table 3). The species richness patterns of grasshoppers/crickets and mosses were least congruent (correlation of 0.303 , $P<0.01$ ), while species diversity of herpetofauna turned out to be highly correlated with that of the dragonflies, and that of grasshoppers/crickets $(0.652, P<0.01$ and 0.643 , $P<0.01$, respectively). The overall number of species of the other groups correlated best with the number of herpetofauna species $(0.820, P<0.01)$.

Species richness models

The stepwise multiple regression models explained between 39.8 (mosses) and $62.8 \%$ (herpetofauna) of the variation in species richness as identified for the five taxonomic groups (Table 4). In general, the regression models explained more of the variation in species richness for taxonomic groups comprising a low number of species than for taxonomic groups with a large number of species (Table 4). When the regression models for each taxonomic group were fitted to the evaluation sets, highly significant correlations between observed and predicted species richness were produced (Table 4). This suggests that the regression models described the observed variation in species richness for all five taxonomic groups adequately.

Habitat heterogeneity was included in the model as prime explanatory variable for three of the five species groups (Table 4). Altitudinal range accounted for most of the variation in species richness of hoverflies. Only for herpetofauna diversity the variables related to heterogeneity of the environment (heterogeneity of habitat or soil types and range in altitude) were not included in an early stage in the stepwise modelling procedure. For this group, climatic conditions (duration of sunshine) seem to be important determinants of the observed pattern but also the percentage of natural area in a grid square explained much of the observed variation in species diversity.

Collinearity between explanatory variables is in some cases highly significant ( 82 significant correlations out of 630 correlations). Heterogeneity of habitat, duration of sunshine, mean altitude and calcareous clay were the variables that most frequently correlated with other environmental variables. 
Table 4 Percentage of explained variance of the environmental variables that were entered in the multiple regression analysis of species diversity for each of the five taxonomic groups

\begin{tabular}{|c|c|c|c|c|c|c|}
\hline \multicolumn{2}{|c|}{ Environmental variable } & \multirow{2}{*}{$\begin{array}{l}\text { Grasshoppers } \\
\text { and crickets }\end{array}$} & \multirow[t]{2}{*}{ Hoverflies } & \multirow[t]{4}{*}{ Dragonflies } & \multirow[t]{2}{*}{ Mossess } & \multirow[t]{2}{*}{ Herpetofauna } \\
\hline Geographical & ALT & & & & & \\
\hline & ALTR & 2.3 & 21.1 & & $2.1 *$ & 1.2 \\
\hline & MLA & & (-) $3.3^{*}$ & & $(-) 1.2 *$ & $(-) 0.4$ \\
\hline \multirow[t]{5}{*}{ Climate } & HUM & $(-) 11$ & (-) 0.8 & & & $(-) 2.5^{*}$ \\
\hline & SUN & $(-) 0.5$ & & $(-) 5.5$ & $(-) 1.9 *$ & (-) 31.6 \\
\hline & RAD & & & $(-) 0.4$ & & \\
\hline & TEMP & 0.5 & & 0.6 & & \\
\hline & PREC & & & & & $1.5 *$ \\
\hline \multirow[t]{7}{*}{ Soil } & HST & $0.3 *$ & 2.6 & 0.3 & & 2.6 \\
\hline & PSS & $(-) 0.6^{*}$ & & & & \\
\hline & CSS & & & & & $(-) 0.8$ \\
\hline & $\mathrm{NCC}$ & & & (-) 2.6 & $(-) 1.1 *$ & \\
\hline & $\mathrm{CC}$ & & & & $(-) 8.3$ & (-) 5.3 \\
\hline & NCL & & 2.8 & $(-) 18$ & & \\
\hline & NAV & $(-) 7.8 *$ & & & 1.3 & $(-) 0.5^{*}$ \\
\hline \multirow[t]{13}{*}{ Habitat } & HLT & 30.0 & & 29.6 & 17.8 & \\
\hline & AGR & & (-) $10.8 *$ & & & \\
\hline & URB & 4.4 & & $0.5^{*}$ & & \\
\hline & DF & 0.9 & 2.1 & $(-) 0.4^{*}$ & 1.5 & \\
\hline & $\mathrm{CF}$ & & $(-) 0.6^{*}$ & $(-) 0.5$ & & $(-) 0.5$ \\
\hline & SAM & & & (-) 0.4 & & 2.1 \\
\hline & DV & $(-) 0.8 *$ & & & 2.4 & \\
\hline & SV & & & & $(-) 0.5^{*}$ & $(-) 0.3$ \\
\hline & MA & & 0.8 & & 1.8 & \\
\hline & $\mathrm{ON}$ & & & $(-) 0.4^{*}$ & & \\
\hline & FW & $(-) 0.6$ & $(-) 0.8$ & & & \\
\hline & SW & & & & & $(-) 0.5$ \\
\hline & $\mathrm{N}$ & & & 0.6 & & 11.9 \\
\hline \multicolumn{2}{|l|}{ No. of species } & 45 & 327 & 72 & 507 & 24 \\
\hline \multicolumn{2}{|c|}{ No. of variables } & 12 & 10 & 14 & 11 & 14 \\
\hline \multicolumn{2}{|c|}{ Explained variance } & $59.7 \%$ & $45.7 \%$ & $60.6 \%$ & $39.8 \%$ & $62.8 \%$ \\
\hline \multicolumn{2}{|c|}{ Spearman $r$ evaluation set } & $0.741 * *$ & $0.639 * *$ & $0.751 * *$ & $0.593 * *$ & $0.765^{* *}$ \\
\hline
\end{tabular}

The four variables explaining most of the variance are given in bold. Between brackets is the effect of the variable on species richness. For a description of the variables see Table 2

* Variable is entered in the model as quadratic term

** Correlation is significant at the 0.01 level

Spatial autocorrelation of residuals

The residuals of all five groups were spatially auto-correlated to a certain degree (Table 5). For the mosses this autocorrelation was strongest and it expanded over a long distance (up to $25 \mathrm{~km}$ ) suggesting that additional factors not included in our analysis are needed to fully 
Table 5 Moran's I values for species richness model residuals

\begin{tabular}{|c|c|c|c|c|c|c|c|}
\hline & \multicolumn{7}{|l|}{ Lags } \\
\hline & 5 & 10 & 15 & 20 & 25 & 30 & 35 \\
\hline Dragonflies & $0.385^{* *}$ & $0.101 * *$ & 0.025 & -0.006 & -0.011 & $-0.033^{* *}$ & $-0.033^{* *}$ \\
\hline Mosses & $0.422^{* *}$ & $0.269^{* *}$ & $0.176^{* *}$ & $0.105^{* *}$ & $0.054 * *$ & 0.016 & $-0.04 * *$ \\
\hline Herpetofauna & $0.276^{* *}$ & $0.119^{* *}$ & $0.093^{* *}$ & $0.066^{* *}$ & $0.038^{* *}$ & -0.002 & -0.018 \\
\hline Grasshoppers and crickets & $0.299 * *$ & $0.202 * *$ & $0.075^{* *}$ & $0.052 * *$ & $0.028^{*}$ & 0.002 & 0.008 \\
\hline Hoverflies & $0.192 * *$ & $0.085^{* *}$ & $<0.001$ & -0.019 & -0.019 & $-0.032 *$ & 0.007 \\
\hline
\end{tabular}

* Correlation is significant at the 0.05 level

** Correlation is significant at the 0.01 level

account for spatial variation in species richness for this group. For all groups spatial autocorrelation of the residuals was strongest in the first two lags $(5-10 \mathrm{~km})$.

\section{Discussion}

In general, patterns in species richness of the five taxonomic groups showed a high degree of congruence. The richness in herpetofauna species correlated best with the overall species richness of the other groups. This congruence is also expressed by the environmental variables that could be held responsible for the formation of these patterns.

Our data suggest that heterogeneity of the environment (in particular habitat heterogeneity) is probably a major determinant of the spatial variation in species richness of the five taxonomic groups under study at the meso-scale $(5 \times 5 \mathrm{~km}$ sampling units $)$ in the Netherlands. Only for herpetofauna diversity the environmental heterogeneity variables (heterogeneity of habitat or soil types and range in altitude) were not entered at an early stage in the stepwise modelling procedure. In general, these findings agree very well with the work of Maes et al. (2005), who studied the species richness patterns of partly the same taxonomic groups in Belgium. They found that for all studied groups (plants, dragonflies, herpetofauna, butterflies and birds) the number of species was positively correlated with biotope diversity. Furthermore, they found a high degree of congruence among the patterns of the different groups. The major difference between the results of Maes et al. (2005) and our study is that they did not find any of the incorporated climatic variables to be of much importance. However, we found that for the herpetofauna the duration of sunshine was strongly negatively correlated with the number of species. This is a remarkable result as the exact opposite would have been more likely since herpetofauna are cold-blooded organisms. It could, however, be that the relationship between herpetofauna species diversity and climate is expressed on a much finer scale and that sandy open areas or the presence of southern exposed slopes are more important than the overall duration of sunshine per year. The other taxonomic group that showed a link with climate were the grasshoppers and crickets. Totally $11 \%$ of the variation in species richness of grasshoppers and crickets can be explained by the relative humidity in spring. Again, this is also a negative relation. The observation that species richness gradients follow that of climate may be valid for a higher scale level (Hawkins et al. 2003; Whittaker et al. 2007) but does not hold true for the Netherlands. A possible explanation lies in the fact that the Netherlands is far from representing a natural system, as $70 \%$ of the country is used for agricultural practices. 
Generally, the soils rich in nutrients have been converted into agricultural land and nature is nowadays restricted mainly to the nutrient poor sandy soils (e.g. Veluwe, dune area). Furthermore, calcareous clay soils often coincide with newly reclaimed land where little time has passed for succession to take place. In other words, there is a complex interplay between natural factors determining biodiversity and environmental degradation and disturbance.

The percentage of the explained variation in species richness was considerably high (between 39.8 and 62.8\%). However, residual analysis showed that a fair amount of spatial autocorrelation remained present in the first two distance classes. In particular in case of the mosses an important explanatory variable seems to be missing; the percentage of explained variation was the lowest $(39.8 \%)$ of all groups, spatial autocorrelation of the residuals was high and the geographical pattern of moss species richness showed a low degree of correlation with species richness of the other groups. Soil moisture and the complexity of vegetation structure are currently not included in the regression analysis, yet could be important factors for the presence of moss species. Besides being an indication that important variables might have been missed, spatial autocorrelation can exaggerate statistical significance and may even influence the order in which variables are included in the model (Diniz-Filho et al. 2003; Whittaker et al. 2007). It might also be sign of systematic spatial patterns in data quality (e.g. Segurado et al. 2006). Shortcomings in data collection most likely contributed to spatial autocorrelation of the observed species richness. Although we tried to account for sampling bias in the species occurrence datasets by selecting the $75 \%$ most frequently surveyed grid squares from each physical geographical region, it is impossible to retrace true sampling intensity from the databases as used in this study. Differences in sampling effort can, however, have a considerable impact on the patterns observed (e.g. Dennis et al. 1999) and consequently on the variables held responsible for the occurrence of these patterns.

Soil type, type of land use, altitude, and climatic variables were for most taxonomic groups more weakly correlated with species richness than variables related to heterogeneity of the environment. This suggests that at the scale level of this study, specialisation and niche differentiation (regarding e.g. physiology, habitat or diet preference, dispersal ability) among the species of a determined taxonomic group may level out the possible effects of environmental variables such as soil type, altitude and temperature on species richness. These factors may have their influence on species composition (as a result of habitat preferences) but if many subsets of species within a taxonomic group prefer different environmental conditions there may be no influence on overall species richness. Heterogeneity of the environment within a grid square allows species with different habitat preferences to occur in that grid square. This study indicates that for the meso-scale level, environmental heterogeneity is expected to be the principle underlying mechanism of overall spatial variation in species richness for a determined taxonomic group, thus explaining why areas with high environmental heterogeneity (e.g. gradient situations) are related to hotspots of biodiversity.

The positive correlation between variables related to environmental heterogeneity and species richness can be explained from two different perspectives. On one hand, species may co-exist because they have different habitat requirements or use different resources. Therefore, differences in the environment are expected to promote co-occurrence of a broad range of species (e.g. Wilson et al. 2004). On the other hand, species may also coexist even when they depend on the same resources. In that case, environmental heterogeneity may be related to the partitioning of limiting resources (more places to nest, feed, hide, etc.), which then prevents domination by a single superior competitor (e.g. 
MacArthur and MacArthur 1961; Shmida and Wilson 1985; Pianka 1966; Rohde 1992; Huston 1994). Whatever explanation is adopted, it is important to note that there is an important trade-off between environmental heterogeneity and habitat fragmentation. Chances of species survival (and, therefore, of species co-existence) decrease as a result of habitat fragmentation, including the conversion, deterioration and isolation of natural habitat patches (Olff and Ritchie 2002; Tews et al. 2004). Also, introducing more environmental heterogeneity into a given area does not necessarily lead to higher species richness as different species experience their environment in a different way. For example, while forest gaps may increase the number of bird and butterfly species by creating habitat heterogeneity, they may have a negative effect on beetle species richness as their habitat became fragmented (Tews et al. 2004). Therefore, the issue of environmental heterogeneity should be considered carefully, especially in the context of nature conservation.

Spatial patterns in species richness of these five groups can be compared to those already described for other groups of organisms. Species richness patterns of vascular plants (van der Meijden et al. 1989) and breeding birds (SOVON vogelonderzoek Nederland 2002) are, for example, also described at a nationwide scale. As mentioned earlier, these groups fulfil a key function in environmental and conservation research and policy. Spatial pattern in species diversity of vascular plant species recorded since 1950 at some points differed considerably from the patterns expressed by the groups studied here. Vascular plant species richness on the sand plateau of the Veluwe in the centre of the country is low, whereas species richness is high for the five taxa in this research. On the other hand, vascular plant species richness is high along the IJssel valley, whereas species richness of the five taxa studied here does not clearly express this pattern. Also, the dune area appears as a much more strongly pronounced hotspot of diversity for vascular plants than for the groups studied here. In some aspects though, there is congruence between the patterns of species richness of vascular plants and those of the five taxa used in this study: the extreme southeastern part of the country, central and southern Brabant, the Meuse valley, and the border of the Veluwe - Utrechtste Heuvelrug - Vechtstreek region are rich in species, while the Peel Horst region, the northern, and northwestern parts of the country are poor in species. The spatial pattern of breeding bird diversity shows little congruence with those of the five groups studied here. Like vascular plants, breeding birds (based on data from 1998 to 2000) show a high concentration of species along the river IJssel. In general, the eastern part of the country is richer in bird species than the western part, again, with exception of the dunes. Areas rich in breeding birds generally represent gradient situations in landscape openness and presence of freshwater bodies. Contrary to all other groups, only few breeding bird species are present in the extreme southeastern part of the country. The one region of the country that can be identified as being important in terms of species diversity of all groups is the Veluwezoom (including the IJssel valley) - Utrechtse Heuvelrug - Vecht region.

This comparison shows that hotspots of species richness do not coincide perfectly for the different groups. This means that developing nature conservation policy upon only few, well-known, taxonomic groups has its limits. The fact that different species groups have different hotspots of diversity has great implications for nature conservation as for example more area is needed in order to preserve the whole range of species.

Acknowledgements Nienke van Geel is thanked for digitizing the climate maps. Jolijn Radix, Marja Seegers and Anouk Cormont are thanked for constructing the map of landscape age. Rogier Donders and Edzer Pebesma are greatly acknowledged for their helpful comments on the statistical analyses. 


\section{References}

Alterra (2001) Het Landelijk grondgebruiksbestand Versie 4 (LGN4). Centrum voor Geo-informatie, Wageningen

Austin MP (1980) Searching for a model for use in vegetation analysis. Vegetatio 42:11-21

Bal D, Beije HM, Fellinger M et al (2001) Handboek Natuurdoeltypen. Report Expertisecentrum LNV, nr. 2001/020. EC-LNV, Wageningen

Bio AMF, Alkemade R, Barendregt A et al (1999) Geostatistical interpolation of abiotic site conditions in the Netherlands. A method for reference mapping. RIVM-report 408657003. RIVM, Bilthoven

Chapin SFIII, Zavaleta ES, Eviner VT et al (2000) Consequences of changing biodiversity. Nature 405 : 234-242. doi:10.1038/35012241

Colwell RK, Lees DC (2000) The mid-domain effect: geometric constraints on the geography of species richness. Trends Ecol Evol 15:70-76. doi:10.1016/S0169-5347(99)01767-X

Cormont A, Radix J, Segers M (2004) The spatial distribution of biodiversity over the Netherlands: the role of landscape age. MSc thesis natural resources management, Utrecht University

Crawley MJ (1993) GLIM for ecologists. Blackwell, London

Currie DJ (1991) Energy and large-scale patterns of animal- and plant-species richness. Am Nat 137:27-49. doi:10.1086/285144

Dennis RLH, Sparks TH, Harvey PB (1999) Bias in butterfly distribution maps: the effects of sampling effort. J Insect Conserv 3:33-42. doi:10.1023/A:1009678422145

Diniz-Filho JA, Bini LM, Hawkins BA (2003) Spatial autocorrelation and red herrings in geographical ecology. Glob Ecol Biogeogr 12:53-64. doi:10.1046/j.1466-822X.2003.00322.x

Dobson AJ (1999) An introduction to generalized linear models. Chapmann and Hall, Boca Raton

Dutilleul P (1993) Modifying the $t$ test for assessing the correlation between two spatial processes. Biometrics 49:305-314. doi:10.2307/2532625

Gaston KJ (2000) Global patterns in biodiversity. Nature 405:220-227. doi:10.1038/35012228

Gaston KJ, Blackburn TM (1990) Effects of scale and habitat on the relationship between regional distribution and local abundance. Oikos 58:329-335. doi:10.2307/3545224

Godfray HCJ, Lawton JH (2001) Scale and species numbers. Trends Ecol Evol 16:400-404. doi:10.1016/ S0169-5347(01)02150-4

Gongrijp GP (1989) Nederland in vorm. Aardkundige waarden van het Nederlandse landschap. Achtergrondreeks Natuurbeleidsplan nr. 5. Ministerie van Landbouw, Natuurbeheer en Visserij, 's-Gravenhage

Harcourt AH (2000) Coincidence and mismatch of biodiversity hotspots: a global survey for the order primates. Biol Conserv 93:163-175. doi:10.1016/S0006-3207(99)00145-7

Hawkins BA, Field R, Cornell HV et al (2003) Energy, water, and broad-scale geographic patterns of species richness. Ecology 84:1608-1623. doi:10.1890/0012-9658(2003)084[1608:PAHAPO]2.0.CO;2

Heikkinen RK, Neuvonen S (1997) Species richness of vascular plants in the subarctic landscape of northern Finland: modelling relationships to the environment. Biodivers Conserv 6:1181-1201. doi:10.1023/ A: 1018356823171

Hubbell SP (2001) The unified neutral theory of biodiversity and biogeography. Princeton University Press, Princeton

Huston MA (1994) Biological diversity: the coexistence of species in changing landscapes. Cambridge University Press, Cambridge

Kerr J (2001) Global biodiversity patterns: from description to understanding. Trends Ecol Evol 16:424-425. doi:10.1016/S0169-5347(01)02226-1

KNMI (2002) Klimaatatlas van Nederland. Elmar, B.V., Rijswijk

Legendre P (1993) Spatial autocorrelation: trouble or new paradigm? Ecology 74:1659-1673. doi:10.2307/ 1939924

Levin SA (1992) The problem of pattern and scale in ecology: the Robbert H. MacArthur award lecture. Ecology 73:1943-1967. doi:10.2307/1941447

Levin SA (2000) Multiple scales and the maintenance of biodiversity. Ecosystems (NY, Print) 3:498-506. doi: $10.1007 / \mathrm{s} 100210000044$

Maes D, Bauwens D, de Bruyn L et al (2005) Species richness coincidence: conservation strategies based on predictive modelling. Biodivers Conserv 14:1345-1364. doi:10.1007/s10531-004-9662-X

MacArthur RH, MacArthur JW (1961) On bird species diversity. Ecology 42:594-598. doi:10.2307/ 1932254

Margules CR, Pressey RL, Williams PH (2002) Representing biodiversity: data and procedures for identifying priority areas for conservation. J Biosci 27:309-326. doi:10.1007/BF02704962

McCullagh P, Nelder JA (1989) Generalized linear models. Chapman and Hall, London 
Millennium Ecosystem Assessment (2005) Ecosystems and human well-being: biodiversity synthesis. World Resources Institute, Washington

Myers N, Mittermeier RA, Mittermeier CG et al (2000) Biodiversity hotspots for conservation priorities. Nature 40:853-858. doi:10.1038/35002501

Nicholls AO (1989) How to make biological surveys go further with generalized linear models. Biol Conserv 50:51-75. doi:10.1016/0006-3207(89)90005-0

Olff H, Ritchie ME (2002) Fragmented nature: consequences for biodiversity. Landsc Urban Plan 58:83-92. doi:10.1016/S0169-2046(01)00211-0

Overbeek GJ, Beusen AHW, Boers PCM et al (2002) Plausibiliteitsdocument STONE 2.0 Globale verkenning van de plausibiliteit van the STONE versie 2.0 voor de modellering van uit- en afspoeling van $\mathrm{N}$ en P. RIVM rapport 718501001 RIVM, Bilthoven

Overmars KP, de Koning GHJ, Veldkamp A (2003) Spatial autocorrelation in multi-scale land use models. Ecol Modell 164:257-270. doi:10.1016/S0304-3800(03)00070-X

Pianka ER (1966) Latitudinal gradients in species diversity: a review of the concepts. Am Nat 100:33-46. doi: $10.1086 / 282398$

Prendergast JR, Quinn RM, Lawton JH et al (1993) Rare species, the coincidence of diversity hotspots and conservation strategies. Nature 365:335-337. doi:10.1038/365335a0

Rahbek C (1995) The elevation gradient of species richness: a uniform pattern? Ecography 18:200-205. doi: 10.1111/j.1600-0587.1995.tb00341.x

Rahbek C, Graves GR (2000) Detection of macro-ecological patterns in South American hummingbirds is affected by spatial scale. Proc R Soc B Biol Sci 267:2259-2265

Rangel TFLVB, Diniz-Filho JAF, Bini LM (2006) Towards an integrated computational tool for spatial analysis in macroecology and biogeography. Glob Ecol Biogeogr 15:321-327. doi:10.1111/j.1466822X.2006.00237.x

Rich TCG (1998) Squaring the circles-bias in distribution maps. Br Wildl 9:213-219

Rohde K (1992) Latitudinal gradients in species diversity: the search for the primary cause. Oikos 65:514-527. doi: $10.2307 / 3545569$

Segurado P, Araujo MB, Kunin WE (2006) Consequences of spatial autocorrelation for niche-based models. J Appl Ecol 43:433-444. doi:10.1111/j.1365-2664.2006.01162.x

Shmida A, Wilson MV (1985) Biological determinants of species diversity. J Biogeogr 12:1-20. doi:10.2307/ 2845026

SOVON vogelonderzoek Nederland (2002) Atlas van de Nederlandse broedvogels 1998-2000. Nederlandse Fauna 5. Nationaal Natuurhistorisch Museum Naturalis, KNNV Uitgeverij \& European Invertebrate Survey-Nederland, Leiden, 584 pp (in Dutch)

Steur GGL, Heijink W (1992) Bodemkaart van Nederland, schaal 1:50.000. Stiboka, Wageningen

Tardif B, DesGranges JL (1998) Correspondance between bird and plant hotspots of the St. Lawrence river and influence of scale on their location. Biol Conserv 84:53-63

Tews J, Brose U, Tielbörger Grimm V et al (2004) Animal species diversity driven by habitat heterogeneity/ diversity: the importance of keystone structures. J Biogeogr 31:79-92

van der Meijden R, Plate CL, Weeda EJ (1989) Atlas van de Nederlandse flora 3. Minder zeldzame en algemene soorten. Leiden: Onderzoekinstituut Rijksherbarium/Hortus Botanicus (in Dutch)

van Nieukerken EJ, van Loon AJ (1995) Biodiversiteit in Nederland. Nationaal Natuurhistorisch Museum, Leiden

Whittaker RJ, Nogués-Bravo D, Araújo MB (2007) Geographical gradients of species richness: a test of water-energy conjecture of Hawkins et al (2003) using European data for five taxa. Global Ecol Biogeogr 16:76-89

Williams PH, Margules CR, Hilbert DW (2002) Data requirements and data sources for biodiversity priority area selection. J Biosci 27:327-338

Wilson RJ, Thomas CD, Fox R et al (2004) Spatial patterns in species distribution reveal biodiversity change. Nature 432:393-396 